\title{
Correction
}

\section{Correction to: The key role of CYC2 during meiosis in Tetrahymena Thermophila}

\author{
Qianlan $\mathrm{Xu}^{1,2,3}$, Ruoyu Wang ${ }^{3}$, A. R. Ghanam ${ }^{3,6}$, Guanxiong Yan ${ }^{4,5}$, Wei Miao ${ }^{4}$, Xiaoyuan Song ${ }^{1,2,3 \bowtie}$ \\ ${ }^{1}$ Hefei National Laboratory for Physical Sciences at the Microscale, University of Science and Technology of China, \\ Hefei 230026, China \\ 2 CAS Center for Excellence in Molecular Cell Science, Shanghai 200031, China \\ ${ }^{3}$ School of Life Sciences, University of Science and Technology of China, Hefei 230071, China \\ ${ }^{4}$ Key Laboratory of Aquatic Biodiversity and Conservation, Institute of Hydrobiology, Chinese Academy of Sciences, \\ Wuhan 430072, China \\ ${ }^{5}$ University of Chinese Academy of Sciences, Beijing 100049, China \\ ${ }^{6}$ Anatomy and Embryology Department, Suez Canal University, Ismailia 41522, Egypt \\ $\bowtie$ Correspondence: songxy5@ustc.edu.cn (X. Song)
}

CORRECTION TO: PROTEIN CELL 2016, 7(4):236-249 HTTPS://DOI.ORG/10.1007/S13238-016-0254-9

In the original publication, the funding information was incorrectly published. The correct funding information is provided in this correction.

This work is supported by grants from the Projects of International Cooperation and Exchanges Ministry of Science and Technology of China (2013DFG32390) and the National Natural Science Foundation of China (31472059) to
X.S. X.S is a recipient of the Young Thousand Talents program (KJ2070000026).

\section{OPEN ACCESS}

This article is distributed under the terms of the Creative Commons Attribution 4.0 International License (http://creativecommons.org/ licenses/by/4.0/), which permits unrestricted use, distribution, and reproduction in any medium, provided you give appropriate credit to the original author(s) and the source, provide a link to the Creative Commons license, and indicate if changes were made. 